\title{
First results of the ORGANIC experiment on EXPOSE-R on the ISS
}

\author{
K.L. Bryson ${ }^{1,2}$, F. Salama' ${ }^{1}$ A. Elsaesser ${ }^{3}$, Z. Peeters ${ }^{4}$, A.J. Ricco ${ }^{5}$, B.H. Foing ${ }^{6}$ and \\ Y. Goreva ${ }^{7}$ \\ ${ }^{1}$ Space Science and Astrobiology Division, NASA Ames Research Center, Moffett Field, CA 94035, USA \\ e-mail: kathryn.bryson@nasa.gov \\ ${ }^{2}$ Bay Area Environmental Research Institute, 625 2nd St, Ste. 209, Petaluma, CA 94952, USA \\ ${ }^{3}$ Leiden Institute of Chemistry, P.O. Box 9502, 2300 RA Leiden, The Netherlands \\ ${ }^{4}$ Department of Terrestrial Magnetism, Carnegie Institute of Washington, 5241 Broad Branch Rd, Washington DC 20015, \\ USA \\ ${ }^{5}$ Small Spacecraft Payloads and Technologies, NASA Ames Research Center, Moffett Field, CA 94035, USA \\ ${ }^{6}$ European Space Agency, ESTEC, 2200 AG Noordwijk, The Netherlands \\ ${ }^{7}$ Department of Mineral Sciences, Smithsonian Institution, Washington, DC 20013-7012, USA
}

\begin{abstract}
The ORGANIC experiment on EXPOSE-R spent 682 days outside the International Space Station, providing continuous exposure to the cosmic-, solar- and trapped-particle radiation background for fourteen samples: 11 polycyclic aromatic hydrocarbons (PAHs) and three fullerenes. The thin films of the ORGANIC experiment received, during space exposure, an irradiation dose of the order of $14000 \mathrm{MJ} \mathrm{m}^{-2}$ over $2900 \mathrm{~h}$ of unshadowed solar illumination. Extensive analyses were performed on the returned samples and the results compared to ground control measurements. Analytical studies of the returned samples included spectral measurements from the vacuum ultraviolet to the infrared range and time-of-flight secondary ion mass spectrometry. Limited spectral changes were observed in most cases pointing to the stability of PAHs and fullerenes under space exposure conditions. Furthermore, the results of these experiments confirm the known trend in the stability of PAH species according to molecular structure: compact PAHs are more stable than non-compact PAHs, which are themselves more stable than PAHs containing heteroatoms, the last category being the most prone to degradation in the space environment. We estimate a depletion rate of the order of $85 \pm 5 \%$ over the 17 equivalent weeks of continuous unshadowed solar exposure in the most extreme case tetracene (smallest, non-compact PAH sample). The insignificant spectral changes (below 10\%) measured for solid films of large or compact PAHs and fullerenes indicate a high stability under the range of space exposure conditions investigated on EXPOSE-R.
\end{abstract}

Received 30 July 2014, accepted 19 October 2014, first published online 25 November 2014

Key words: astrobiology, EXPOSE-R, fullerenes, International Space Station, ORGANIC experiment, PAHs, photolysis, solar exposure.

\section{Introduction}

Aromatic compounds are among the most abundant organic materials in space (Tielens 2008). Polycyclic aromatic hydrocarbons (PAHs) have been identified from their vibrational bands in many space environments and are estimated to make up $\sim 15 \%$ of the cosmic carbon fraction (Leger \& d'Hendecourt 1985; Salama et al. 1996; Salama 2008; Tielens 2008). PAHs are also present in Solar System materials such as meteorites (Sephton et al. 1998), the outer Solar System satellites (Cruikshank et al. 2008), and possibly in comets (Keller et al. 2006; Sandford et al. 2010). Circumstellar regions of carbon stars support chemical reactions that lead to the formation of complex carbon compounds, the nature and structure of which are strongly influenced by physical and chemical parameters such as temperature, density and composition (Pascoli \& Polleux 2000; Cherchneff 2011; Contreras \& Salama 2013). At condensation temperatures higher than $3500 \mathrm{~K}$ and when hydrogen is absent, polyynes cross-link to form fullerenes (Cataldo 2004; Jäger et al. 2008, 2009).
Laboratory studies and theoretical calculations have informed our knowledge of the size and charge-state distribution of interstellar PAHs (e.g. Salama et al. 1996; Allamandola et al. 1999; Ruiterkamp et al. 2005; Montillaud et al. 2013). In the interstellar medium (ISM), PAHs are expected to be present as a mixture of free, neutral and ionized molecules ranging from small, gas-phase molecules $(<20$ carbon atoms) to large clusters. In astronomical environments of strong ultraviolet (UV) irradiation, PAH molecules can be partly dehydrogenated or fragmented (Allain et al. 1996a, b; Vuong \& Foing 2000; Le Page et al. 2001; Malloci et al. 2008). The measured abundance of any particular PAH isomer depends on its formation, destruction, ionization rates and hydrogenation state. UV survival of PAHs relative to their ionization and/or dehydrogenation properties has been studied in the context of the search for these species in the diffuse ISM (e.g. Ehrenfreund et al. 1995) or by probing environmental effects on the diffuse interstellar band (DIB) carriers (Sonnentrucker et al. 1997). The physical conditions in the ISM can favour individual 
Table 1. Overview of samples and locations in carrier (Fig. 2)

\begin{tabular}{|c|c|c|}
\hline PAH (formula) & Configuration & Closed cell location \\
\hline Tetracene $\left(\mathrm{C}_{18} \mathrm{H}_{12}\right)$ & Four ring catacondensed linear & $4 \& 19$ \\
\hline Chrysene $\left(\mathrm{C}_{18} \mathrm{H}_{12}\right)$ & Four ring catacondensed branched & 2 \\
\hline Perylene $\left(\mathrm{C}_{20} \mathrm{H}_{12}\right)$ & Five ring pericondensed compact & $5 \& 20$ \\
\hline Coronene $\left(\mathrm{C}_{24} \mathrm{H}_{12}\right)$ & Seven ring pericondensed compact & $1 \& 15$ \\
\hline Diphenanthro[9,10-b:9'10'-d] thiophene $\left(\mathrm{C}_{28} \mathrm{H}_{16} \mathrm{~S}\right)$ & Seven ring catacondensed non-compact & 6 \\
\hline Ovalene $\left(\mathrm{C}_{32} \mathrm{H}_{14}\right)$ & Ten ring pericondensed compact & 7 \\
\hline Circobiphenyl $\left(\mathrm{C}_{38} \mathrm{H}_{16}\right)$ & Ten ring pericondensed compact & 13 \\
\hline Dinaphtho[8,1,2-abc: $\left.2^{\prime}, 1^{\prime}, 8^{\prime}-\mathrm{klm}\right]$ coronene $\left(\mathrm{C}_{36} \mathrm{H}_{16}\right)$ & 11 ring pericondensed compact & 16 \\
\hline Dibenzo[jk, a'b']octacene $\left(\mathrm{C}_{40} \mathrm{H}_{22}\right)$ & Ten ring pericondensed non-compact & 14 \\
\hline Tetrabenzo[de,no,st,c'd']heptacene $\left(\mathrm{C}_{42} \mathrm{H}_{22}\right)$ & 11 ring pericondensed non-compact & 8 \\
\hline Dicoronylene $\left(\mathrm{C}_{48} \mathrm{H}_{20}\right)$ & 15 ring pericondensed compact & 9 \\
\hline $\mathrm{C}_{60}$ & 20 hexagons +12 pentagons & 10 \\
\hline $\mathrm{C}_{70}$ & 25 hexagons +12 pentagons & 11 \\
\hline $\mathrm{C}_{60} / \mathrm{C}_{70} / \mathrm{C}_{84}$ mixture & & 12 \\
\hline
\end{tabular}

PAHs or PAH classes (Ruiterkamp et al. 2005). Two DIBs in the near infrared (IR) are thought to be associated with the $\mathrm{C}_{60}$ cation (Foing \& Ehrenfreund 1994, 1997, Galazutdinov et al. 2000), leading to an estimate of up to $1 \%$ of interstellar carbon being in the form of $\mathrm{C}_{60}{ }^{+}$. Fullerene compounds containing $\mathrm{C}_{60}$ and $\mathrm{C}_{70}$ neutral molecules have also been reported from their vibrational signature in the IR spectra of the young planetary nebula Tc 1 (Cami et al. 2010) and there is evidence of their presence in other sources (e.g. Sellgren et al. 2010).

The abundance and stability of PAHs in the space environment make them prime components in the pathways of cosmic carbon chemistry (Tielens 2008). Fullerenes constitute only a small fraction of cosmic carbon, but their recent detection in planetary nebula provides important constraints for their versatile chemistry in various space environments (Ehrenfreund \& Foing 2010; Bernard-Salas et al. 2012). Better knowledge of the stability of these molecules is therefore crucial to our understanding of the evolution of organics in space. UV photolysis and cosmic-ray bombardment predominantly govern the destruction of large organic molecules in space. The full range of energies, fluxes and radiation types present in the space environment cannot be readily simulated in laboratory facilities on the ground, making in situ space experiments a priority (Guan et al. 2010).

The study of astronomically relevant PAHs and fullerenes led us to propose a series of experiments to be implemented in Earth-orbital space, utilizing the Columbus precursor flight opportunities announced in 1992. The ORGANICS experiment on the BIOPAN/FOTON capsule (Ehrenfreund et al. 2007) was flown as a precursor experiment for the ORGANIC experiment on the EXPOSE-R multi-user facility on the International Space station (ISS). Samples for ORGANIC consist of thin films of PAHs deposited onto $\mathrm{MgF}_{2}$ windows via vacuum sublimation as described in Bryson et al. 2011. A detailed discussion of the flight sample preparation, including pre-flight ultraviolet-visible (UV-vis) characterization of the samples and ground control monitoring spectroscopy experiments for ORGANIC measured over 19 months, has been provided in a previous report (Bryson et al. 2011). Here, we report results derived from the analysis of the returned samples. Demets et al. (this volume) discuss the possible interference of contaminants affecting the open sample cells of several EXPOSE-R experiments and the resulting general loss in transmission at shorter wavelengths. As a result, in this paper we only present and discuss qualitatively the results derived from the analysis of the returned closed sample cells, which were not contaminated. Further investigations are required to fully assess the effects of possible contamination on the open-cell samples.

\section{Experimental details}

\section{ORGANIC experiment}

The ORGANIC experiment exposed thin films (typically 100$300 \mathrm{~nm}$ ) of selected PAH and fullerene-type molecules to an interplanetary environment in low-Earth orbit (LEO) on the EXPOSE-R facility of the European Space Agency ESA on the ISS (Bryson et al. 2011). EXPOSE-R is a multi-user facility mounted on an external platform of the Service Module Zvezda, part of the Russian Segment of the ISS. The facility allows defined long-term exposure experiments to solar UV under space vacuum or a defined atmosphere. The ORGANIC experiment spent 682 days outside the ISS, providing continuous exposure to the cosmic-, solar- and trappedparticle radiation background and $\sim 2900 \mathrm{~h}$ of unshadowed solar illumination with a calculated total (full-spectrum) irradiation dose of $\sim 14000 \mathrm{MJ} \mathrm{m}^{-2}\left(\sim 60 \mathrm{MJ} \mathrm{m}^{-2}\right.$ of UV-C; $\sim 1100 \mathrm{MJ} \mathrm{m}^{-2}$ for all wavelengths $<400 \mathrm{~nm}$ ) (Rabbow et al. this issue).

The ORGANIC experiment on EXPOSE-R consists of 14 samples: 11 selected PAHs and the fullerenes $\mathrm{C}_{60}, \mathrm{C}_{70}$ and a $\mathrm{C}_{60} / \mathrm{C}_{70} / \mathrm{C}_{84}$ mixture (see Table 1 ). The samples were exposed to UV and particle radiation in the ISS environment in a closed- or open-cell arrangement (Fig. 1). A carrier with identical samples - not exposed to UV irradiation - was mounted below the carrier. These samples were designated 'Dark' samples. Testing the relative stability of these PAH molecules should provide insight into extraterrestrial organic photochemistry. Due to the large number of PAH isomers, it is neither 

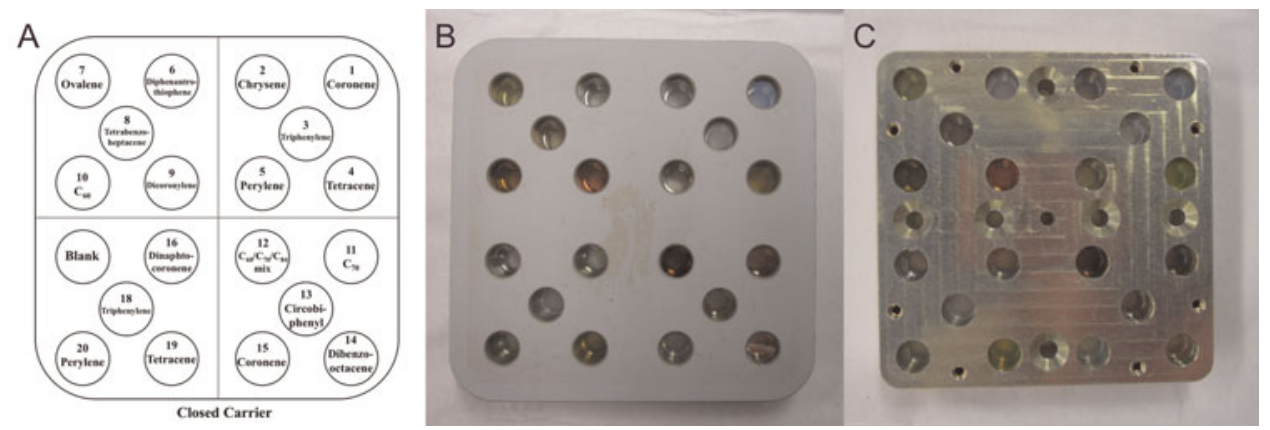

Fig. 1. (A) Layout of the closed carrier. Some molecules are present in duplicate within the closed-cell sample carrier (including tetracene, perylene and coronene). Due to problems with the deposition of triphenylene, the sample is not presented in this report. (B, C) Returned sample carriers with closed sample cells of the ORGANIC experiment exposed on the ISS in the EXPOSE-R facility for 18 months. (B) Flight UV carrier; (C) Flight Dark carrier (located below the Flight UV samples, exposed to cosmic radiation but not to UV irradiation).

feasible to map the spectra nor to conduct space exposure of all possible structures. A series of structures representative of various classes of PAHs were chosen, including small and large pericondensed species (or compact PAHs), catacondensed and branched (linear) PAHs, commonly referred to as noncompact PAHs (Salama et al. 1996 and references therein) and PAHs containing heteroatoms. All trays carry both solar-irradiation-exposed and dark samples shielded from UV photons, enabling discrimination between the effects of exposure to solar photons and cosmic rays (Fig. 1). The thin films were deposited in a vacuum sublimation system to a thickness of 100 and $300 \mathrm{~nm}$ as described in Bryson et al. (2011).

As noted above, post-flight investigations revealed contamination in the ISS environment affecting the EXPOSE-R sample carriers. Two major routes of contamination, external and internal, were identified during post-flight examination of returned space hardware of EXPOSE-R. External contamination most likely originated from nearby venting ports and thrusters of the ISS and/or from combustion products released by arriving or leaving vehicles. Internal contamination is suspected to be due to outgassing compounds from the EXPOSE-R facility as well as from the samples they contained, which polymerized in the presence of UV radiation. More details are provided in Demets et al. in this volume. As a result, the possibility cannot be entirely excluded that changes or lack thereof observed in the absorbances of the samples could be affected by a contamination layer on the outside windows of the EXPOSE-R facility, limiting the penetration of UV photons (Cottin et al. this volume; Demets et al. this volume).

During space exposure, several windows of UV-exposed samples from experiments other than ORGANIC acquired brown shading on their inward-facing sides, indicating contamination from the interior of the EXPOSE-R facility. The observed discoloration was caused by a homogenous film of cross-linked organic polymers (Demets et al. this volume). Figure 2 presents a schematic drawing of a possible contamination scenario. Samples of the ORGANIC experiment integrated into closed sample cells were not affected by this contamination, as the rear (uncoated) window protects the sample (see Fig. 2). Due to these contamination issues on the
EXPOSE-R facility, we present only the results of the closed sample cells of the ORGANIC experiment. We note that the presence of contaminants may have affected the irradiation flux that impacts the samples with a general loss in transmission at shorter wavelengths as described by Demets et al. (this volume) that prevents a full quantitative analysis of the return samples.

\section{Mission Ground Reference and Ground Control Samples}

Mission Ground Reference sample carriers were exposed with a time shift of 2 years, relative to the ISS exposures, in a planetary simulation chamber at the Microgravity User Support Center (MUSC) at the German Aerospace Center (DLR). Vacuum, UV radiation and temperature fluctuations were simulated according to the telemetry data measured during flight. Samples from these carriers will be referred to as Experiment Sequence Test (EST) samples. EST UV samples were irradiated with a Solar simulator for $13722 \mathrm{~h}$ with an irradiation dose of $1300 \mathrm{MJ} \mathrm{m}^{-2}$ in the range $200-400 \mathrm{~nm}$, which is very similar to the $993 \mathrm{MJ} \mathrm{m}^{-2}$ exposure outside ISS for wavelengths $<400 \mathrm{~nm}$, although the simulated solar spectrum lacks the high-energy but low total irradiance contribution due to the Lyman- $\alpha$ hydrogen emission. As in the ISS flight experiment, EST Dark samples were located in close proximity to the UV-photolysed EST samples but were completely shielded from UV exposure.

In addition to the EST samples, a complete set of Ground Control Samples was stored under dark conditions at room temperature in a desiccator from the time of film deposition in August 2009. Spectra indicate that the thin films have remained stable over a period of 5 years thus far, as described in Bryson et al. (2011).

\section{$U V$-vis spectroscopy of returned carriers}

UV-vis absorbance was collected for the returned and EST sample carriers in the Astrophysics and Astrochemistry Laboratory at NASA Ames Research Center. Spectra of the films in the sealed cells in the sample carrier were recorded using an Ocean Optics HR4000 UV-vis spectrometer equipped with a Velmex high-precision $x-y-z$ translation 
A. Closed Cell

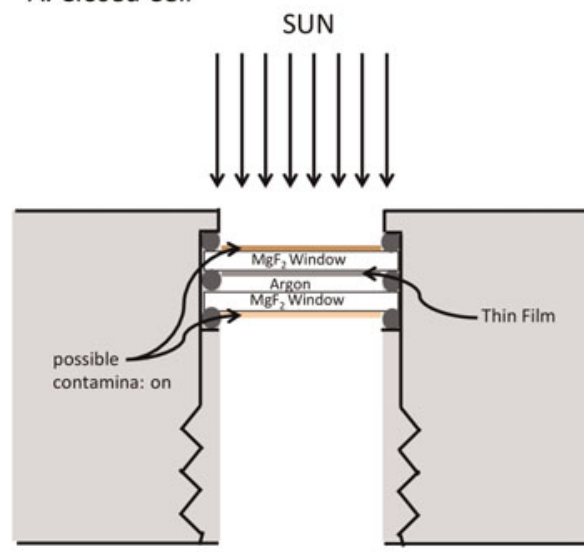

EXPOSE-R facility and ISS Environment
B. Open Cell

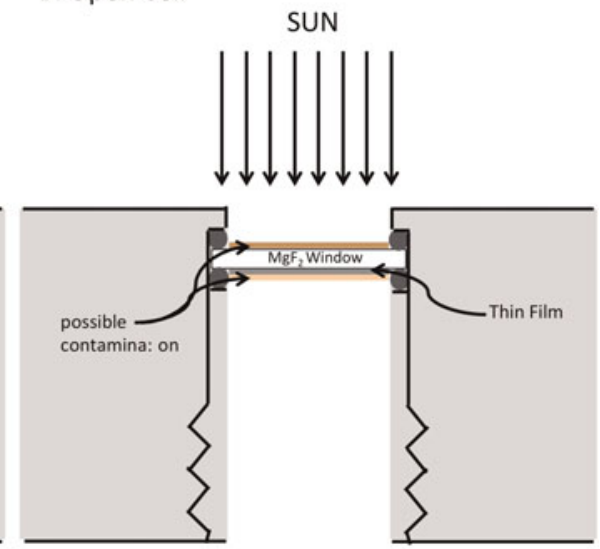

EXPOSE-R facility and ISS Environment

Fig. 2. Post-flight investigations indicated a contamination issue (see Demets et al. this volume). Displayed is a schematic drawing of closed sample cells (A) and open sample cells (B) of the EXPOSE-R facility. The UV radiation enters through the $\mathrm{MgF}_{2}$ window and penetrates the thin-film samples. Contaminants from the outside environment of the ISS and/or the interior of the EXPOSE-R facility may be present as indicated above (for details see Demets et al. this volume). In the open sample cells, contaminants from the interior of the EXPOSE-R carrier could form an additional layer in direct contact with the thin-film sample. In the closed sample cell configuration, the thin films are protected from direct contact to the contaminants (see also Figure 6).

stage. The spectral light source was an Ocean Optics DH-2000-S-DUV Deuterium Tungsten Halogen light source, which combines the continuous spectra of deuterium and tungsten-halogen light sources in a single optical path, providing wavelength coverage in the $190-1700 \mathrm{~nm}$ range. The HR4000 UV-vis spectrometer has a 300 lines $\mathrm{mm}^{-1}$ variable blazed grating and $10 \mu \mathrm{m}$ entrance aperture. It has a spectral coverage of 200-1100 nm and an optical resolution of 0.91 $\mathrm{nm}$ (full-width at half-maximum). The spectrometer includes an SMA 905 fibre connector that aligns the entrance slit and fibre, ensuring fibre concentricity. One of the blank sealed cells in the sample carrier was used as the reference to compute absorbance.

\section{Fourier transform infrared (FTIR) spectroscopy of returned carriers}

A Digilab FTIR spectrometer was used for IR measurements. The Velmex high-precision $x-y-z$ translation stage was also used with this spectrometer to handle the carriers inside an Ar-filled glove bag. A total of 256 scans at a resolution of $0.5 \mathrm{~cm}^{-1}$ were averaged for the reported spectra. The resulting spectra were filtered and baseline-corrected for presentation purposes using the Digilab Resolutions Pro software. As in the UV-vis spectra, a blank-sealed cell was utilized as the reference.

Vacuum ultraviolet ( $V U V$ ) spectroscopy of returned carriers VUV absorption of the open cells was measured at the synchrotron facility at ISA, Centre for Storage Ring Facilities, Aarhus University (AU), Denmark (Miles et al. 2007, 2008). The AU-UV beamline is designed for circular dichroism and UV spectroscopy with a typical flux of $2 \times 10^{11}$ photons $\mathrm{s}^{-1}$. The samples were measured in a nitrogen-purged chamber and the spectra were recorded in the VUV wavelength region, from 120 to $250 \mathrm{~nm}$, at a spectral resolution of $1 \mathrm{~nm}$.

\section{Time-of-flight secondary-ion mass spectrometry (TOF-SIMS) of returned carriers}

Analyses were performed using a TOF-SIMS IVt (ION-TOF $\mathrm{GmbH})$ spectrometer. Ion imaging was performed using a $25 \mathrm{keV}$ clustered $\mathrm{Bi}^{3+}$ beam at a pulsed current of $0.3 \mathrm{pA}$, rastered over areas of $150 \times 150 \mu \mathrm{m}$ for $\sim 100 \mathrm{~s}$. A clustered beam minimizes molecular fragmentation by the ion beam. The accumulated primary ion dose never exceeded $1.25 \times 10^{10}$ ions $\mathrm{cm}^{-2}$, which is below the static limit (the point where the same location is statistically sampled more than once) of $10^{12}$ ions $\mathrm{cm}^{-2}$ for organic molecules. Analyses were performed with the instrument optimized for high mass resolution (bunched mode: $m / \Delta m$ of at least $\sim 8000$ at $\mathrm{m} / z$ 30, where $m$ is the mass of the molecular fragment and $z$ its charge).

\section{Results and discussion}

\section{$U V$-vis spectroscopy}

Figures 3-5 show the spectra collected for selected samples described in Bryson et al. (2011). The spectra for the other 11 samples are provided in supplementary figures S1-S11 online. In these figures, the top panel shows the absorption spectra of the samples while the bottom panel presents the calculated residual spectra that illustrate the effects (or lack thereof) of UV photolysis and/or cosmic radiation: (1) the effects of space UV photolysis alone were revealed by subtracting spectra of Flight Dark from Flight UV samples; (2) the effects of cosmic radiation alone were examined by subtracting spectra of Ground Control or EST Dark from Flight Dark samples; (3) the combined effects of UV photolysis and cosmic radiation together were revealed 

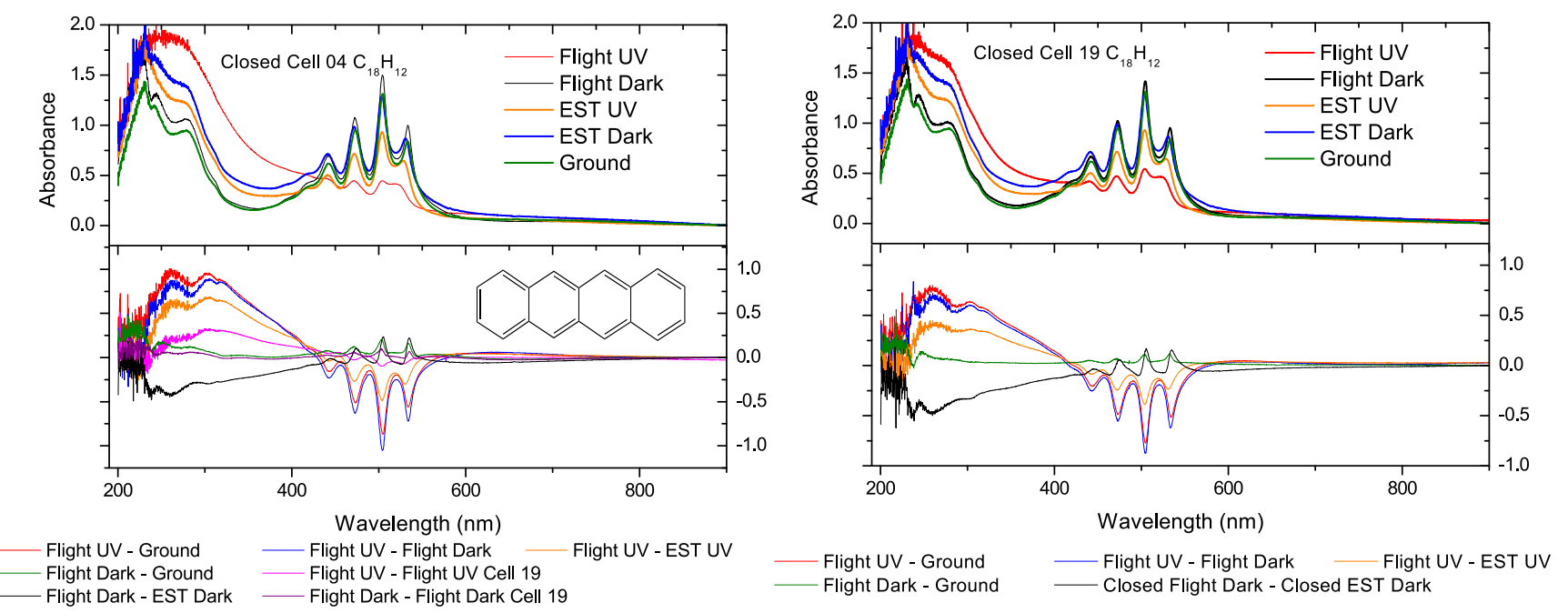

Fig. 3. UV-vis spectra of tetracene films deposited on $\mathrm{MgF}_{2}$ disks integrated into two different closed sample cells at positions 4 and 19 (top panels) and calculated residual spectra (bottom panels). The samples exposed to space conditions (Flight UV) show strong changes in absorbance due to UV photolysis leading to absorbance spectral residuals of the order of $10-20 \%$ for bands in the $400-600 \mathrm{~nm}$ range that correspond to a depletion rate of $85 \pm 5 \%$ over the 17 equivalent weeks of continuous unshadowed solar exposure.

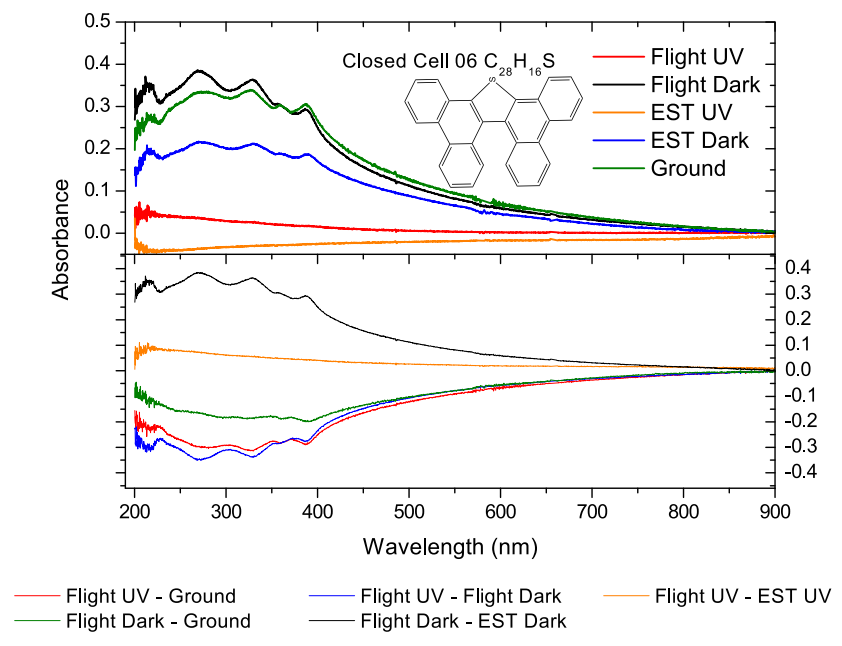

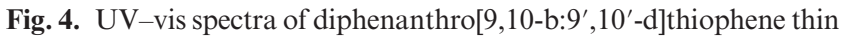
films deposited on $\mathrm{MgF}_{2}$ disks integrated into sample cells (top panel) and residual spectra (bottom panel), which provide evidence for significant depletion ( $>95 \%$ as we cannot measure any of the corresponding spectral bands) of this specific PAH molecule in the UV-exposed sample cells. Diphenanthro[9,10-b:9'10'-d]thiophene is non-compact, includes a hetero atom, and is expected to be less stable than compact PAHs.

by subtracting spectra of Ground Control from Flight UV samples; and (4) the effects of solar irradiation outside the ISS were compared to the effects of the Solar Simulator by subtracting spectra of EST UV from Flight UV samples. In some instances, nominally identical samples, or the same compound with different deposited thicknesses, were compared for identical space exposures by taking the difference of their spectra; these results are also included in the bottom panels of Figs. 3-5.

The UV-vis spectral characteristics of the closed-cell sample films indicate that most of the samples are stable under space

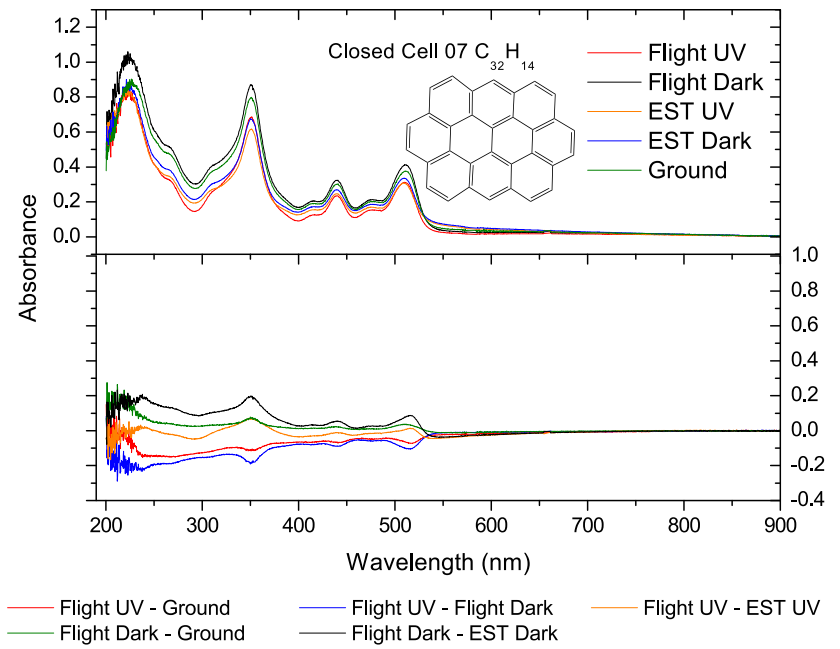

Fig. 5. UV-vis spectra of ovalene thin films deposited on $\mathrm{MgF}_{2}$ disks integrated into sample cells (top panel) and calculated residual spectra (bottom panel). The residual spectra show minor depletion $(<10 \%)$ of ovalene thin films in the UV-exposed flight cells.

exposure conditions. Tetracene, molecular formula (MF) $\mathrm{C}_{18} \mathrm{H}_{12}$, (Fig. 3) shows the most depletion due to UV irradiation (Flight UV-Flight Dark), a result that is expected due to its small size and its linear structure. Diphenanthro [9,10-b:9',10'-d]thiophene, a non-compact hetero PAH of MF $\mathrm{C}_{28} \mathrm{H}_{16} \mathrm{~S}$ (Fig. 4), shows also an increased loss of absorbance due to UV photon radiation (Flight UV-Flight Dark). Ovalene, however, which is a compact, and hence more stable $\mathrm{PAH}$ of $\mathrm{MF}_{32} \mathrm{H}_{14}$ (Fig. 5), shows small spectral changes of ovalene thin films subjected to UV photolysis in the space environment. The absorption band peaks and band systems were previously discussed in detail for all samples (Bryson et al. 2011), and are listed for all the samples in Table 2. Some 
Table 2. Overview of $U V-V i s$ band peaks

\begin{tabular}{|c|c|c|c|c|c|c|c|}
\hline PAH (formula) & Phase & $\begin{array}{l}\text { Band system } \\
1(\mathrm{~nm})\end{array}$ & $\begin{array}{l}\text { Band system } \\
2(\mathrm{~nm})\end{array}$ & $\begin{array}{l}\text { Band system } \\
3(\mathrm{~nm})\end{array}$ & $\begin{array}{l}\text { Band system } \\
4(\mathrm{~nm})\end{array}$ & References & Stability \\
\hline \multirow[t]{3}{*}{ Tetracene $\left(\mathrm{C}_{18} \mathrm{H}_{12}\right)$} & Flight UV & & 278 & $414,440,472,504,522$ & & P.S. & Significant depletion \\
\hline & Flight Dark & & 278 & $400,420,442,472,504,532$ & & P.S. & \\
\hline & Ground & 221 & 278 & $400,420,442,472,504,532$ & & Bryson et al. (2011) & \\
\hline \multirow[t]{3}{*}{ Chrysene $\left(\mathrm{C}_{18} \mathrm{H}_{12}\right)$} & Flight UV & 272 & 304,317 & $338,348,357,366$ & 405,480 & P.S. & Minor depletion \\
\hline & Flight Dark & 272 & 304,317 & $338,348,357,366$ & 405,480 & P.S. & \\
\hline & Ground & $216,246,272$ & 304,317 & $338,348,357,366$ & 405,480 & Bryson et al. (2011) & \\
\hline \multirow[t]{3}{*}{ Perylene $\left(\mathrm{C}_{20} \mathrm{H}_{12}\right)$} & Flight UV & & 263,300 & $328,342,384,435,467$ & & P.S. & Stable \\
\hline & Flight Dark & & 263,300 & $328,342,384,435,467$ & & P.S. & \\
\hline & Ground & 210 & 263,300 & $328,342,384,435,467$ & & Bryson et al. (2011) & \\
\hline \multirow[t]{3}{*}{ Coronene $\left(\mathrm{C}_{24} \mathrm{H}_{12}\right)$} & Flight UV & 315 & 373 & 409 & & P.S. & Stable \\
\hline & Flight Dark & 315 & 373 & 409 & & P.S. & \\
\hline & Ground & 315 & 373 & 409 & & Bryson et al. (2011) & \\
\hline \multirow{3}{*}{$\begin{array}{l}\text { Diphenanthro[9,10-b:9'10'-d] } \\
\text { thiophene }\left(\mathrm{C}_{28} \mathrm{H}_{16} \mathrm{~S}\right)\end{array}$} & $\begin{array}{l}\text { Deposition } 1 \\
\text { Flight UV }\end{array}$ & & 264 & 323 & 358,386 & P.S. & Significant depletion \\
\hline & Flight Dark & & 269 & 326 & 357,386 & P.S. & Signitit a \\
\hline & Ground & 209 & 269 & 326 & 357,386 & Bryson et al. (2011) & \\
\hline \multirow[t]{3}{*}{ Ovalene $\left(\mathrm{C}_{32} \mathrm{H}_{14}\right)$} & Flight UV & 265 (sh), 311 (sh), 350 & $416(w), 439$ & 476,510 & & P.S. & Stable \\
\hline & Flight Dark & 265 (sh), 311 (sh), 350 & $416(w), 439$ & 476,510 & & P.S. & \\
\hline & Ground & 219,265 (sh), 311 (sh), 350 & $416(w), 439$ & 476,510 & & Bryson et al. (2011) & \\
\hline \multirow[t]{3}{*}{ Circobiphenyl $\left(\mathrm{C}_{38} \mathrm{H}_{16}\right)$} & Flight UV & 364 & 407 & 455 & & P.S. & Stable \\
\hline & Flight Dark & 364 & 407 & 455 & & P.S. & \\
\hline & Ground & 364 & 407 & 455 & & Bryson et al. (2011) & \\
\hline \multirow{3}{*}{$\begin{array}{l}\left.\text { Dinaphtho[8,1,2-abc:2', } 1^{\prime}, 8^{\prime}-\mathrm{klm}\right] \\
\text { coronene }\left(\mathrm{C}_{36} \mathrm{H}_{16}\right)\end{array}$} & Flight UV & 258,287 (sh) & 377 & 444,464 & & P.S. & Stable \\
\hline & Flight Dark & 258,287 (sh) & 377 & 444,464 & & P.S. & \\
\hline & Ground & $258,287(\mathrm{sh})$ & 377 & 444,464 & & Bryson et al. (2011) & \\
\hline \multirow{3}{*}{$\begin{array}{l}\text { Dibenzo[jk,a'b'] } \\
\text { octacene }\left(\mathrm{C}_{40} \mathrm{H}_{22}\right)\end{array}$} & Flight UV & & & & & P.S. & Moderate depletion \\
\hline & Flight Dark & & & & & P.S. & \\
\hline & Ground & 196,226 & 278 & 351 & & Bryson et al. (2011) & \\
\hline Tetrabenzo[de,no,st,c'd'] & Flight UV & & 280 & 381 & & P.S. & Moderate depletion \\
\hline \multirow[t]{2}{*}{ heptacene $\left(\mathrm{C}_{42} \mathrm{H}_{22}\right)$} & Flight Dark & 225 & 281 & 381 & & P.S. & \\
\hline & Ground & 225 & 281 & 381 & & Bryson et al. (2011) & \\
\hline \multirow[t]{3}{*}{ Dicoronylene $\left(\mathrm{C}_{48} \mathrm{H}_{20}\right)$} & Flight UV & & 247,288 & 342,360 & 464 (b), $544 \mathrm{~nm}$ & P.S. & Stable \\
\hline & Flight Dark & & 247,288 & 342,360 & 464 (b), $544 \mathrm{~nm}$ & P.S. & \\
\hline & Ground & 201 & 247,288 & 342,360 & 464 (b), $544 \mathrm{~nm}$ & Bryson et al. (2011) & \\
\hline \multirow[t]{3}{*}{$\mathrm{C}_{60}$} & Flight UV & & 270 & 345 & 435,615 & P.S. & Stable \\
\hline & Flight Dark & & 270 & 345 & 435,615 & P.S. & \\
\hline & Ground & 223 & 270 & 345 & 435,615 & Bryson et al. (2011) & \\
\hline \multirow[t]{3}{*}{$\mathrm{C}_{70}$} & Flight UV & 214 & 237 & - & - & P.S. & Stable $^{\mathrm{a}}$ \\
\hline & Flight Dark & & 250,337 & 383 & 475 & P.S. & \\
\hline & Ground & 218 & 250,337 & 383 & 475 & Bryson et al. (2011) & \\
\hline \multirow[t]{3}{*}{$\mathrm{C}_{60} / \mathrm{C}_{70} / \mathrm{C}_{84}$ mixture } & Flight UV & & 270 & 345 & 440,615 & P.S. & Stable \\
\hline & Flight Dark & & 270 & 345 & 440,615 & P.S. & \\
\hline & Ground & 218 & 270 & 345 & 440,615 & Bryson et al. (2011) & \\
\hline
\end{tabular}

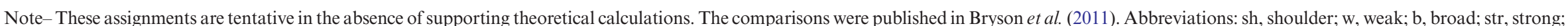
P.S., Present Study.

${ }^{\mathrm{a}}$ The disappearance of specific $\mathrm{C}_{70}$ bands at 330 and $380 \mathrm{~nm}$ is reminiscent of spectral changes reported during the formation of the $\mathrm{C}_{140}$ dimer (Lebedkin et al. 2000). 


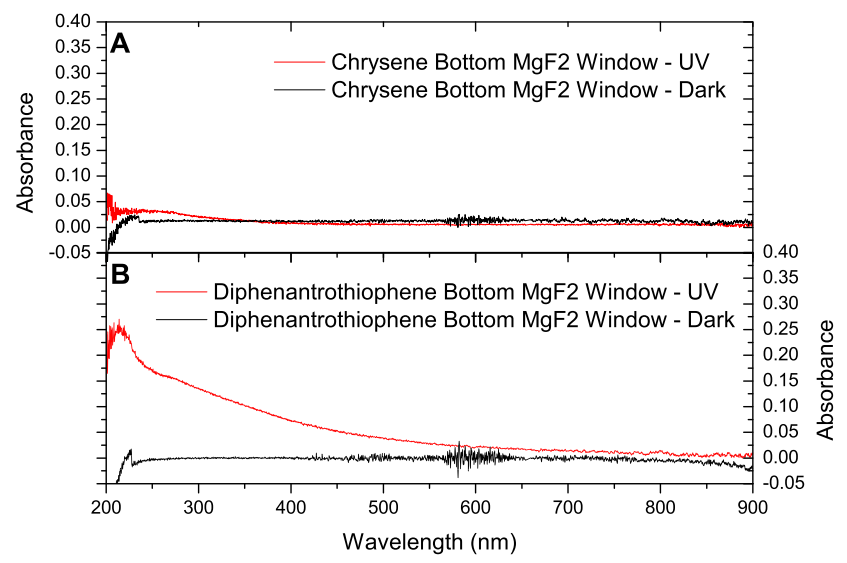

Fig. 6. Example of UV-vis spectra of the bottom (rear, nominally uncoated) windows of closed cells. Panel (A) shows no change in absorbance of the rear window of the chrysene closed cell, where little spectral change of the sample was observed as a result of UV exposure. Panel (B) shows that the depleted sample of UV-exposed diphenanthro [9,10-b:9'10'-d]thiophene also displays a general loss in transmission on the outside rear window (due to internal contamination from the EXPOSE facility, see section on ORGANIC Experiment). Although it does not affect the spectral results from our closed cells, this measurement proves that UV penetrates both windows and polymerizes the contamination layer on the outside rear window. This general loss in transmission at shorter wavelengths is described by Demets et al. this volume.

peaks listed in Table 2 fall outside the wavelength range of the spectrometer system $(220-900 \mathrm{~nm})$ and do not appear in the spectra shown in the figures.

\section{$U V-v i s$ spectroscopy and contamination}

In order to verify that the samples in the closed cells did not evaporate and redeposit on the rear (nominally uncoated) windows, spectra were collected of the individual windows after opening the cells. For samples where no significant degradation was observed, no redeposition was observed (for example, see Fig. 6(a)). In the samples where significant depletion of the sample is observed after space exposure (e.g. diphenanthro [9,10-b:9'10'-d]thiophene, see Fig. 4), no features of the original deposited sample are present on the rear window. However, a general loss in transmission toward shorter wavelengths is observed for the rear window, confirming the contamination effect described in the section ORGANIC Experiment by Demets et al. (this volume)

\section{Additional analysis techniques}

To further confirm the diagnostics derived from UV-vis spectroscopy measurements, additional analyses were performed on selected samples. The additional analytical studies included IR spectroscopy measurements of all carriers, VUV spectroscopy measurements of the open flight carriers at the synchrotron facility ASTRID, and TOF-SIMS analysis. Selected spectra are shown to illustrate the cases. The spectra for the other samples are also provided in supplementary figures online.

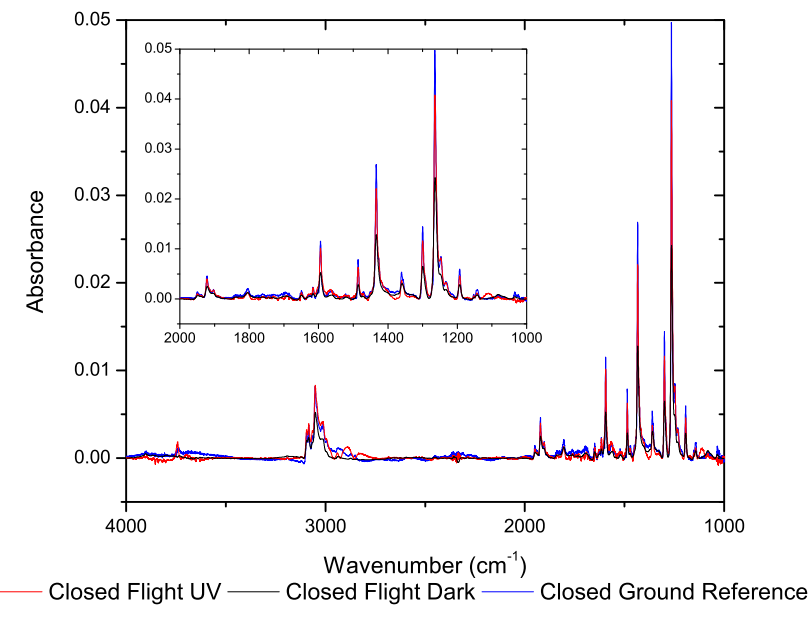

Fig. 7. Comparison of the FTIR spectra of thin films of chrysene $\left(\mathrm{C}_{18} \mathrm{H}_{12}\right)$ for flight UV-exposed (red), Flight Dark (black), and Ground Control (blue) cells. Minimal spectral variations and no new bands associated with photoproducts are observed, indicating that the sample is stable to exposure to the near-ISS space environment.

\section{IR spectroscopy}

The IR spectra of Chrysene are shown in Fig. 7. Main absorption band peak positions are listed in Table 3 for three representative samples. The peaks have been matched to spectral positions reported in the literature (Hudgins \& Sandford 1998; Schettino et al. 2002; Boersma et al. 2013; Mattioda et al. 2014), taking into account the shifts expected for thin films and the fact that the samples were exposed to air and therefore water before flight. No peaks are observed at higher energies than $4000 \mathrm{~cm}^{-1}$ (Fig. 7). Based on comparison with published data, the IR spectra of the samples exhibit minimal spectral variations. No new bands that can be associated with photoproducts were observed. These observations are in agreement with the conclusions derived from the UV-vis spectra: the samples undergo only minor degradation as a result of space exposure in the ISS environment.

\section{Vacuum $U V$-vis spectroscopy}

The VUV spectra of ovalene are presented in Fig. 8. Although the VUV spectra were only collected for open flight carriers, we present the results nonetheless because they offer an additional region of the spectrum. The spectra show little change due to space exposure and no new additional features are observed. The ovalene spectra shown in Fig. 8 indicates that the samples are stable and confirm the diagnostics derived from UV-vis and FTIR measurements for compact regular PAHs. The spectra measured at the synchrotron facility match well the spectra published in the literature (Malloci et al. 2004).

\section{TOF-SIMS of tetracene}

The space-exposed and ground control samples of tetracene $\left(\mathrm{C}_{18} \mathrm{H}_{12}\right)$ were analysed with TOF-SIMS in order to further investigate the observed degradation and to characterize UV penetration of this sample. The examined flight samples showed deterioration of the originally deposited material. 
Table 3. Overview of IR band peaks in selected samples (chrysene, dibenzo [jk, a', b']octacene and $C_{60}$ )

\begin{tabular}{|c|c|c|c|c|c|c|c|}
\hline \multicolumn{2}{|l|}{ Reference spectra $^{1}$} & \multicolumn{2}{|c|}{ Closed flight UV } & \multicolumn{2}{|c|}{ Closed flight dark } & \multicolumn{2}{|c|}{ Ground } \\
\hline wavenumber $\left(\mathrm{cm}^{-1}\right)$ & Intensity $\left(\mathrm{km} \mathrm{mol}^{-1}\right)$ & $\mathrm{cm}^{-1}$ & Peak absorbance & $\mathrm{cm}^{-1}$ & Peak absorbance & $\mathrm{cm}^{-1}$ & Peak absorbance \\
\hline \multicolumn{8}{|l|}{ Chrysene } \\
\hline 1162.8 & 0.45752 & 1144 & $1.15 \times 10^{-3}$ & 1143 & $8.37 \times 10^{-4}$ & 1141 & $1.78 \times 10^{-3}$ \\
\hline $1193.4^{\mathrm{a}}$ & 4.5752 & 1193 & $4.59 \times 10^{-3}$ & 1193 & $2.86 \times 10^{-3}$ & 1193 & $5.98 \times 10^{-3}$ \\
\hline $1235.9^{\mathrm{a}}$ & 4.5752 & & & & & & \\
\hline 1264 & 10.234 & 1265 & $4.08 \times 10^{-2}$ & 1264 & $2.43 \times 10^{-2}$ & 1265 & $4.97 \times 10^{-2}$ \\
\hline $1270.6^{\mathrm{a}}$ & 2.2876 & & & & & & \\
\hline 1302.3 & 2.2876 & 1361 & $3.72 \times 10^{-3}$ & 1359 & $3.06 \times 10^{-3}$ & 1361 & $5.38 \times 10^{-3}$ \\
\hline 1429.7 & 18.06 & 1434 & $2.21 \times 10^{-2}$ & 1434 & $1.28 \times 10^{-2}$ & 1434 & $2.69 \times 10^{-2}$ \\
\hline 1490.6 & 12.642 & 1486 & $6.29 \times 10^{-3}$ & 1486 & $2.86 \times 10^{-3}$ & 1486 & $7.87 \times 10^{-3}$ \\
\hline 1523.2 & 1.1438 & & & & & & \\
\hline \multirow[t]{2}{*}{$1601.2^{\mathrm{a}}$} & 6.622 & 1594 & $1.02 \times 10^{-2}$ & 1594 & $5.26 \times 10^{-3}$ & 1594 & $1.15 \times 10^{-2}$ \\
\hline & & 1805 & $1.32 \times 10^{-3}$ & 1804 & $1.25 \times 10^{-3}$ & 1803 & $2.10 \times 10^{-3}$ \\
\hline \multirow[t]{3}{*}{$1946.1^{\mathrm{a}}$} & 4.5752 & 1922 & $4.01 \times 10^{-3}$ & 1921 & $2.51 \times 10^{-3}$ & 1922 & $4.62 \times 10^{-3}$ \\
\hline & & 3012 & $4.16 \times 10^{-3}$ & 3012 & $2.20 \times 10^{-3}$ & 3012 & $3.89 \times 10^{-3}$ \\
\hline & & 3020 & $4.10 \times 10^{-3}$ & 3020 & $2.21 \times 10^{-3}$ & 3020 & $3.67 \times 10^{-3}$ \\
\hline \multirow[t]{3}{*}{$3063.9^{\mathrm{b}}$} & 126.42 & 3051 & $8.33 \times 10^{-3}$ & 3051 & $5.23 \times 10^{-3}$ & 3052 & $8.20 \times 10^{-3}$ \\
\hline & & 3084 & $3.95 \times 10^{-3}$ & 3084 & $2.34 \times 10^{-3}$ & 3084 & $3.75 \times 10^{-3}$ \\
\hline & & 3094 & $3.26 \times 10^{-3}$ & 3094 & $2.06 \times 10^{-3}$ & 3094 & $2.92 \times 10^{-3}$ \\
\hline \multicolumn{8}{|c|}{ dibenzo[jk, $\left.a^{\prime}, b^{\prime}\right]$ octacene ${ }^{2}$} \\
\hline 1120.1 & 9.88 & 1115 & $3.04 \times 10^{-3}$ & 1117 & $3.20 \times 10^{-4}$ & 1116 & $9.92 \times 10^{-4}$ \\
\hline 1133.6 & 16.028 & & & & & & \\
\hline 1168.4 & 5.973 & & & & & & \\
\hline 1190 & 4.497 & 1189 & $2.06 \times 10^{-4} \times 10^{-4}$ & 1189 & $1.20 \times 10^{-3}$ & 1190 & $1.70 \times 10^{-3}$ \\
\hline 1214.3 & 1.043 & & & & & & \\
\hline 1238.2 & 3.21 & & & & & & \\
\hline 1249.5 & 1.632 & & & & & & \\
\hline 1285.5 & 41.272 & 1285 & $4.15 \times 10^{-3}$ & 1285 & $1.84 \times 10^{-3}$ & 1285 & $3.80 \times 10^{-3}$ \\
\hline 1310.2 & 8.714 & & & & & & \\
\hline 1327.8 & 3.928 & & & & & & \\
\hline 1340.8 & 3.886 & & & & & & \\
\hline 1344.5 & 4.33 & 1360 & $6.50 \times 10^{-4}$ & 1361 & $5.30 \times 10^{-4}$ & 1361 & $9.48 \times 10^{-4}$ \\
\hline 1383.1 & 0.974 & & & & & & \\
\hline 1409.1 & 53.473 & & & & & & \\
\hline 1416.4 & 5.661 & & & & & & \\
\hline 1423.5 & 8.758 & & & & & & \\
\hline 1436.9 & 92.302 & 1433 & $1.17 \times 10^{-3}$ & 1432 & $2.67 \times 10^{-3}$ & 1432 & $4.31 \times 10^{-3}$ \\
\hline 1465.8 & 1.909 & 1476 & $2.32 \times 10^{-4}$ & 1522 & $3.28 \times 10^{-4}$ & 1522 & $4.18 \times 10^{-4}$ \\
\hline 1528.6 & 6.371 & & & & & & \\
\hline 1560.8 & 4.496 & & & & & & \\
\hline 1571.1 & 34.45 & & & & & & \\
\hline 1584.9 & 0.768 & & & & & & \\
\hline 1593.6 & 4.877 & & & & & & \\
\hline 1599.7 & 9.67 & 1596 & $2.32 \times 10^{-3}$ & 1594 & $4.82 \times 10^{-4}$ & 1593 & $9.16 \times 10^{-4}$ \\
\hline 1612.3 & 12.859 & & & & & & \\
\hline 1629.1 & 3.499 & & & & & & \\
\hline 1634.7 & 7.966 & & & & & & \\
\hline 1669.7 & 7.719 & & & & & & \\
\hline 1688.6 & 15.502 & 1672 & $1.77 \times 10^{-3}$ & 1673 & $8.76 \times 10^{-4}$ & 1673 & $1.55 \times 10^{-3}$ \\
\hline 1709.7 & 2.896 & & & & & & \\
\hline 1732.2 & 1.998 & 1740 & $1.25 \times 10^{-3}$ & 1733 & $2.75 \times 10^{-4}$ & 1724 & $5.44 \times 10^{-4}$ \\
\hline 1793 & 14.316 & & & 1793 & $1.93 \times 10^{-4}$ & 1796 & $3.10 \times 10^{-4}$ \\
\hline 1851.7 & 11.247 & 1851 & $2.09 \times 10^{-4}$ & 1845 & $1.66 \times 10^{-4}$ & 1845 & $1.71 \times 10^{-4}$ \\
\hline 1903.8 & 4.267 & & & & & & \\
\hline 1926.1 & 5.894 & & & 1917 & $2.03 \times 10^{-4}$ & 1916 & $2.40 \times 10^{-4}$ \\
\hline \multirow[t]{2}{*}{1937.4} & 5.177 & & & & & & \\
\hline & & 2817 & $1.35 \times 10^{-4}$ & & & & \\
\hline 2962.2 & 2.004 & 2888 & $2.73 \times 10^{-4}$ & 2853 & $1.15 \times 10^{-4}$ & 2850 & $4.70 \times 10^{-4}$ \\
\hline 3031.1 & 43.351 & 3016 & $7.68 \times 10^{-4}$ & 2925 & $3.09 \times 10^{-4}$ & 2919 & $6.05 \times 10^{-4}$ \\
\hline 3061.5 & 111.67 & 3046 & $8.40 \times 10^{-4}$ & 3047 & $1.34 \times 10^{-3}$ & 3047 & $1.41 \times 10^{-3}$ \\
\hline 3094.7 & 35.592 & $3742^{\mathrm{d}}$ & $1.74 \times 10^{-3}$ & & & $3745^{\mathrm{d}}$ & $3.64 \times 10^{-4}$ \\
\hline
\end{tabular}


Table 3. (Cont.)

\begin{tabular}{|c|c|c|c|c|c|c|c|}
\hline \multicolumn{2}{|l|}{ Reference spectra $^{1}$} & \multicolumn{2}{|c|}{ Closed flight UV } & \multicolumn{2}{|c|}{ Closed flight dark } & \multicolumn{2}{|c|}{ Ground } \\
\hline wavenumber $\left(\mathrm{cm}^{-1}\right)$ & Intensity $\left(\mathrm{km} \mathrm{mol}^{-1}\right)$ & $\mathrm{cm}^{-1}$ & Peak absorbance & $\mathrm{cm}^{-1}$ & Peak absorbance & $\mathrm{cm}^{-1}$ & Peak absorbance \\
\hline \multicolumn{8}{|l|}{$C_{60}{ }^{3}$} \\
\hline 1073 & & 1065 & $3.38 \times 10^{-4}$ & 1071 & $1.06 \times 10^{-3}$ & 1071 & $2.15 \times 10^{-3}$ \\
\hline 1105 & & 1118 & $4.39 \times 10^{-3}$ & 1120 & $1.14 \times 10^{-3}$ & 1119 & $2.27 \times 10^{-3}$ \\
\hline \multicolumn{8}{|l|}{1177} \\
\hline 1190 & & 1183 & $3.19 \times 10^{-3}$ & 1182 & $7.92 \times 10^{-3}$ & 1183 & $1.06 \times 10^{-2}$ \\
\hline \multicolumn{8}{|l|}{1220} \\
\hline 1251 & & 1257 & $3.10 \times 10^{-3}$ & 1269 & $2.86 \times 10^{-3}$ & 1267 & $4.66 \times 10^{-3}$ \\
\hline \multicolumn{8}{|l|}{1277} \\
\hline \multicolumn{8}{|l|}{1308} \\
\hline \multicolumn{8}{|l|}{1343} \\
\hline \multicolumn{8}{|l|}{1345} \\
\hline 1426 & & 1378 & $2.18 \times 10^{-3}$ & 1378 & $1.38 \times 10^{-3}$ & 1376 & $2.09 \times 10^{-3}$ \\
\hline 1431 & & 1429 & $7.27 \times 10^{-3}$ & 1429 & $9.69 \times 10^{-3}$ & 1429 & $1.33 \times 10^{-2}$ \\
\hline \multicolumn{8}{|l|}{1435} \\
\hline \multicolumn{8}{|l|}{1473} \\
\hline \multicolumn{8}{|l|}{1507} \\
\hline 1535 & & 1539 & $6.23 \times 10^{-4}$ & 1539 & $1.29 \times 10^{-3}$ & 1539 & $2.07 \times 10^{-3}$ \\
\hline \multicolumn{8}{|l|}{1576} \\
\hline \multicolumn{8}{|l|}{1585} \\
\hline & & 1729 & $1.13 \times 10^{-2}$ & 1728 & $6.12 \times 10^{-3}$ & 1729 & $9.80 \times 10^{-3}$ \\
\hline & & & & 2077 & $4.55 \times 10^{-4}$ & 2077 & $5.61 \times 10^{-4}$ \\
\hline & & & & 2191 & $6.25 \times 10^{-4}$ & 2191 & $8.46 \times 10^{-4}$ \\
\hline & & 2847 & $1.85 \times 10^{-3}$ & 2849 & $3.05 \times 10^{-3}$ & 2849 & $3.61 \times 10^{-3}$ \\
\hline & & 2918 & $3.14 \times 10^{-3}$ & 2920 & $6.23 \times 10^{-3}$ & 2921 & $7.70 \times 10^{-3}$ \\
\hline & & $2950^{\mathrm{c}}$ & $1.78 \times 10^{-3}$ & $2951^{\mathrm{c}}$ & $3.65 \times 10^{-3}$ & $2951^{\mathrm{c}}$ & $5.25 \times 10^{-3}$ \\
\hline & & $3743^{\mathrm{d}}$ & $1.88 \times 10^{-3}$ & & & $3736^{\mathrm{d}}$ & $7.28 \times 10^{-4}$ \\
\hline
\end{tabular}

${ }^{1}$ Boersma et al. 2013, Hudgins \& Sandford 1998.

${ }^{2}$ Boersma et al. 2013, Mattioda et al. 2014.

${ }^{3}$ Schettino et al. (2002).

${ }^{\text {a }}$ Position of strongest band in a set of 'complex' band features.

${ }^{\mathrm{b}}$ Major feature in the $\mathrm{CH}$ stretching region.

${ }^{\mathrm{c}}$ The feature at $3000 \mathrm{~cm}^{-1}$ is also present in pre-flight FTIR spectra and therefore most likely a contamination and not part of the $\mathrm{C}_{60}$ spectra.

${ }^{\mathrm{d}}$ The $\sim 3750 \mathrm{~cm}^{-1}$ feature is representative of problems with our purge system and not of the sample.

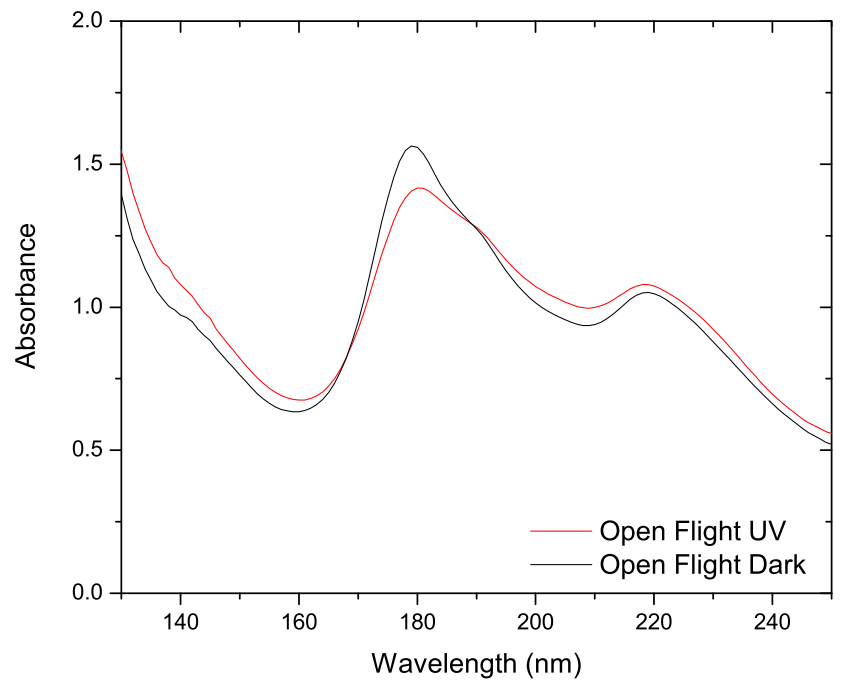

Fig. 8. VUV spectra of thin films of ovalene from open Flight UV-exposed (red) and open Flight Dark (black) cells measured at the ASTRID synchrotron facility.
Figure 9 shows the TOF-SIMS spectra of tetracene $\left(\mathrm{C}_{18} \mathrm{H}_{12}\right)$ : ground control (top panel) and flight (bottom panel) samples. Tetracene has a monoisotopic mass of $228.09 \mathrm{amu}$, the main peak displayed in the ground control sample (Fig. 9). $\mathrm{C}_{18} \mathrm{H}_{10}, \mathrm{C}_{17} \mathrm{H}_{11}$ and $\mathrm{C}_{16} \mathrm{H}_{10}$ are common fragments of the molecule, and their intensities relative to tetracene are less than $10 \%$. The spectrum of the space-exposed sample shows that although a fraction of tetracene is preserved, fragments of the molecule become significantly more abundant during space exposure $\left(\mathrm{C}_{17} \mathrm{H}_{11}\right.$ intensity is up to 50 from $10 \%$ in the ground control samples), consistent with the depletion of the starting material as revealed by the UV-vis spectra (Fig. 3). This strongly suggests molecular fragmentation occurred during exposure to the space environment. Since TOF-SIMS analyses the region of the thin film furthest from the supporting $\mathrm{MgF}_{2}$ window, the fragmentation pattern in Fig. 9 indicates penetration of solar UV photons through the entire thin film.

We used tetracene to estimate the level of sample depletion for three reasons: (i) tetracene is a prototype for small (four ring), non-compact PAHs and, as such, it can provide an upper limit on the extent of degradation to be expected for regular PAHs when exposed to the space (ISS) environment; (ii) 


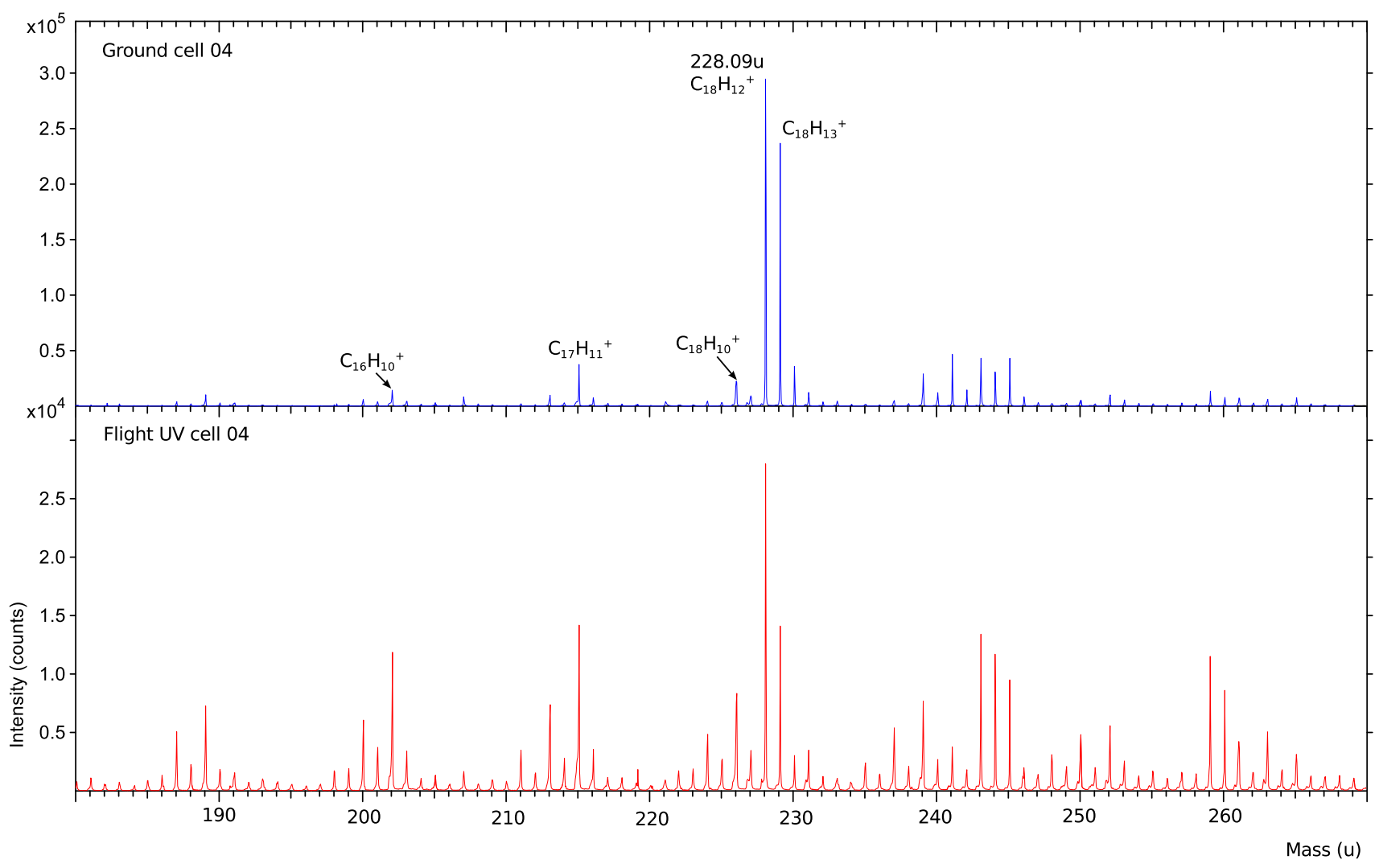

Fig. 9. TOF-SIMS positive spectra of a tetracene thin film exposed to UV radiation (bottom panel) and ground control (top panel). They indicate products with loss of $\mathrm{H}_{2}, \mathrm{CH}$ and $2 \times \mathrm{CH}$.

the absorption spectrum of tetracene in the UV-Vis (Fig. 3) exhibits a set of four discrete absorption bands that can be easily used as a tracer of the changes induced in the sample by exposure to the space (ISS) environment; and (iii) tetracene was measured in closed cells at two positions (cells 4 and 19; Fig. 1), increasing the 'statistical' accuracy of the measurements. By measuring the loss in absorbance normalized to the total band absorbance for each of the four absorption bands in the two closed cells, we derive an average of $10-20 \%$ residual of the tetracene thin film over the continuous exposure to the cosmic-, solar- and trapped-particle radiation background. This degradation due to UV photolysis is confirmed by high-resolution TOF-SIMS measurements, see Fig. 9, with loss of $\mathrm{H}, \mathrm{H}_{2}$, $\mathrm{CH}$ and $2 \times \mathrm{CH}$. This is consistent with predictions that in astronomical environments characterized by high levels of UV irradiation, $\mathrm{PAH}$ molecules can be expected to be partly dehydrogenated or fragmented (Allain et al. 1996a, b; Vuong \& Foing 2000; Le Page et al. 2001; Malloci et al. 2008).

Effects induced by UV exposure: comparing dark and exposed flight samples

We measured the UV absorbances for specific bands and compared the dark flight samples and the ground samples. For such pairs of samples, the ratio of absorbances is between 0.9 and 1.1, indicating a good stability of flight samples not exposed to UV light, and providing an estimate of reproducibility of sample absorbance measurement with an uncertainty below 0.1 .
For compact PAHs, the survival rates are high (estimated by ratios of UV absorbances exposed/dark), indicating good stability to UV exposure. For non-compact PAHs, the survival rates are lower, indicating fragility under UV exposure. The Buckyball $\mathrm{C}_{60}$ also shows high stability, while the $\mathrm{C}_{70}$ spectra indicate a depletion of absorbance that could be interpreted as being due to the formation of the dimer $C_{140}$ (Lebedkin et al. 2000).

The differences observed among PAHs might be explained by differences in 'atom loss' properties of the various species. In particular, Jochims et al. (1994) calculated the critical internal energy $E c$ for $\mathrm{H}$ atom loss for various PAHs. They estimated $E c=8.26 \mathrm{eV}$ for tetracene, a non-compact PAH and $E c=10.6$ $\mathrm{eV}$ for coronene, a compact PAH. This seems consistent with the relative survival of these two UV-exposed compounds, and with the detection of dehydrogenated products in the measured TOF-SIMS for the exposed tetracene film (Figure 9).

The superior UV survival of chrysene compared with that of its tetracene isomer measured on EXPOSE-R and in the laboratory is consistent with a more effective vibrational relaxation process precluding dissociative loss of $\mathrm{H}$. This is also consistent with ionization and dehydrogenation processes reported by Vuong \& Foing (2000) and Le Page et al. (2001).

\section{Summary and conclusions}

A set of measurements and analyses has been performed on the returned samples from the ORGANIC experiment on the 
EXPOSE facility, comparing dark and exposed flight samples. The returned samples were also compared to the ground control measurements discussed in Bryson et al. (2011). The analytical studies relied primarily on spectral measurements of the thin films in the UV and visible, and included VUV and IR spectroscopy measurements as well as analyses of tetracene with mass spectrometry (TOF-SIMS).

Samples were also compared to ground control samples and samples in simulated UV and temperature conditions ('EST' samples). In most cases, the samples exhibit minimal spectral variations in the UV-vis range when exposed to the radiation environment outside the ISS. The minor degradation observed in the UV-vis absorbance of the original samples and the fact that no new bands could be associated with photoproducts all point to the known stability of PAHs and fullerenes, which undergo only minor degradation upon exposure to the LEO radiation environment.

We report the following findings from these exposure experiments:

(1) Observations and measurements point to the high stability of the PAH and fullerene solid films under space exposure.

(2) The expected trend in the stability of PAHs as a function of size, structure and composition (Pullman \& Pullman 1955; Gutman \& Cyvin 1989) is observed. Thin films of compact regular PAHs such as perylene, coronene, ovalene, circobiphenyl, dinaphtocoronene, dicoronylene and the fullerenes are found to be the most stable, followed by non-compact (branched and linear) PAHs such as tetracene, chrysene, dibenzooctacene and tetrabenzoheptacene that exhibit some minor level of degradation. Hetero PAHs, i.e. PAHs that include a heteroatom in their molecular structure such as diphenanthrothiophene, are the most fragile and show the highest degradation rate with exposure. To learn more about the time profile of sample depletion and the formation rate of secondary products onboard spectral measurements such as performed with $\mathrm{O} /$ OREOS nanosatellite and as proposed for future exposure experiments on the ISS are required.

\section{Supplementary materials}

Supplementary material accompanies this paper on the Journal's website (http://journals.cambridge.org/IJA).

\section{Acknowledgements}

The authors acknowledge the support of ESA Human Spaceflight and Microgravity Programme and NASA's Science Mission Directorate through the Astronomy and Physics Research and Analysis (APRA) and NASA Astrobiology Institute (NAI) programmes. We acknowledge the NASA Astrobiology Institute and the Netherlands Space Office NSO as funding sources. The authors thank E.P. Monaghan and D. Wills for their support in the flight preparations and E. Jessberger, A. Bischoff, M. Breitfellner and F. Robert. The authors acknowledge the outstanding technical support provided by R. Walker in the Astrophysics and Astrochemistry Laboratory at NASA Ames Research Center. The authors acknowledge Sloan Foundation and Deep Carbon Observatory for funding TOF-SIMS analyses. We gratefully acknowledge the beam time allocated at the synchrotron facility ASTRID and thank Søren V. Hoffmann and Nykola C. Jones for their valuable support. We thank Pascale Ehrenfreund (PI of ORGANIC experiment on EXPOSE-R on ISS).

\section{References}

Allain, T., Leach, S. \& Sedlmayr, E. (1996a). Photodestruction of PAHs in the interstellar medium. I. Photodissociation rates for the loss of an acetylenic group. Astron. Astrophys. 305, 602-615.

Allain, T., Leach, S. \& Sedlmayr, E. (1996b). Photodestruction of PAHs in the interstellar medium. II. Influence of the states of ionization and hydrogenation. Astron. Astrophys.305, 616-630.

Allamandola, L.J., Hudgins, D.M. \& Sandford, S.A. (1999). Modeling the unidentified infrared emission with combinations of polycyclic aromatic hydrocarbons. Astrophys. J. 511, 115-119.

Bernard-Salas, J., Cami, J., Peeters, E., Jones, A.P., Micelotta, E.R. \& Groenewegen, M.A.T. (2012). On the excitation and formation of circumstellar fullerenes. Astrophys. J. 757, 41-51.

Boersma, C., Bauschlicher, C.W. Jr., Ricca, A., Mattioda, A.L., Cami, J., Peeters, E., Sánchez de Armas, F., Puerta Saborido, G., Hudgins, D.M. \& Allamandola, L.J. (2013). The NASA Ames PAH IR Spectroscopic database version 2.00: updated content, website and on/offline tools. Astrophys. J. Suppl. 211(1), 8-20.

Bryson, K.L., Peeters, Z., Salama, F., Foing, B., Ehrenfreund, P., Ricco, A. J., Jessberger, E., Bischoff, A., Breitfellner, M., Schmidt, W., Robert, F. (2011). The ORGANIC experiment on EXPOSE-R on the ISS: flight sample preparation and ground control spectroscopy. Adv. Space Res. 48, 1980-1996.

Cami, J., Bernard-Salas, J., Peeters, E. \& Malek, S.E. (2010). Detection of $\mathrm{C}_{60}$ and $\mathrm{C}_{70}$ in a Young Planetary Nebula. Science 329(5996), 1180-1182.

Cataldo, F. (2004). From elemental carbon to complex macromolecular networks in space. In Astrobiology: Future Perspectives, ed. Ehrenfreund et al., pp. 97-126. Astrophysics and Space Science Library 305, Kluwer Academic Publishers, Dordrecht.

Cherchneff, I. (2011). In EAS Publications Series, Vol. 46, PAHs and the Universe, ed. Joblin, C. \& Tielens, A.G.G.M., Cambridge: Cambridge University Press.

Contreras, C. \& Salama, F. (2013). Laboratory investigations of polycyclic aromatic hydrocarbon formation and destruction in the circumstellar outflows of carbon stars. Astrophys. J. Suppl. 208, 6-22.

Cottin, H., Saiagh, K., Cloix, M., Cloix, M., Khalaf, D., Macari, F., Jérome, M., Polienor, J.-M., Bénilan, Y., Coll, P. et al. (2014). The AMINO Experiment: a laboratory for Astrochemistry and Astrobiology on the EXPOSE-R facility of the International Space Station. Int. J. Astrobiol., 13(5).

Cruikshank, D.P., Wegryn, E., Dalle Ore, C.M., Brown, R.H., Bibring, J.-P., Buratti, B.J., Clark, R.N., McCord, T.B., Nicholson, P.D., Pendleton, Y.J. et al. (2008). Hydrocarbons on Saturn's satellites Iapetus and Phoebe. Icarus 193, 334-343.

Demets, R., Bertrand, M., Bolkhovitinov, A., Bryson, K., Colas, C., Cottin, H., Dettmann, J., Ehrenfreund, P., Elsaesser, A., Jaramillo, E. et al. (2014). Window contamination on Expose-R. Int. J. Astrobiol., 13(5).

Ehrenfreund, P. \& Foing, B.H. (2010). Fullerenes and cosmic carbon. Science 329(5996), 1159-1160.

Ehrenfreund, P., Foing, B.H., d'Hendecourt, L., Jenniskens, P. \& Desert, F.-X. (1995). Search for coronene and ovalene cations in the diffuse interstellar medium. Astron. Astrophys. 299, 213-221. 
Ehrenfreund, P., Ruiterkamp, R., Peeters, Z., Foing, B., Salama, F. \& Martins, Z. (2007). The ORGANICS experiment on BIOPAN V: UV and space exposure of aromatic compounds. PSS 55, 383-400.

Foing, B.H. \& Ehrenfreund, P. (1994). Detection of two interstellar absorption bands coincident with spectral features of $\mathrm{C}_{60}{ }^{+}$. Nature $\mathbf{3 6 9}$, 296-298.

Foing, B.H. \& Ehrenfreund, P. (1997). New evidences for interstellar $\mathrm{C}_{60}^{+}$ Astron. Astrophys. 317, 59-62.

Galazutdinov, G.A., Krełowski, J., Musaev, F.A., Ehrenfreund, P. \& Foing, B.H. (2000). On the identification of the $\mathrm{C}_{60}^{+}$interstellar features. Mon. Not. R. Astron. Soc. 317, 750-758.

Guan, Y.Y., Fray, N., Coll, P., Macari, F., Chaput, D., Raulin, F. \& Cottin, H. (2010). UVolution: compared photochemistry of prebiotic organic compounds in low Earth orbit and in the laboratory. Planet. Space Sci. 58, 1327-1346.

Gutman, I. \& Cyvin, S.J. (1989). Extraterrestrial Benzenoid Hydrocarbons In Introduction to the Theory of Benzenoid Hydrocarbons, ed. Gutman, I. \& Cyvin, I., Springer, Heidelberg, 93-116.

Hudgins, Sandford (1998). Infrared spectroscopy of matrix isolated polycyclic aromatic hydrocarbons. 1. PAHs containing two to four rings. J. Phys. Chem. 102, 329-343.

Jäger, C., Mutschke, H., Llamas-Jansa, I., Henning, T. \& Huisken, F. (2008). Laboratory analogs of carbonaceous matter: soot and its precursors and by-products. Proc. IAU Symp. 251, 425-432.

Jäger, C., Huisken, F., Mutschke, H., Llamas Jansa, I. \& Henning, T. (2009). Formation of polycyclic aromatic hydrocarbons and carbonaceous solids in gas-phase condensation experiments. Astrophys. J. 696, 706-712.

Jochims, H.W., Ruhl, E., Baumgartel, H., Tobita, S. \& Leach, S. (1994). Size effects on dissociation rates of polycyclic aromatic hydrocarbon cations: laboratory studies and astrophysical implications. Astrophys. J. 420, 307-317.

Keller, L.P., Bajt, S., Baratta, G.A., Borg, J., Bradley, J.P., Brownlee, D.E., Busemann, H., Brucato, J.R., Burchell, M., Colangeli, L. et al. (2006). Infrared spectroscopy of comet 81P/Wild 2 samples returned by stardust. Science 314, 1728-1731.

Lebedkin, S., Hull, W.E., Soldatov, A., Renker, B. \& Kappes, M.M. (2000). Structure and properties of the Fullerene Dimer $\mathrm{C}_{140}$ produced by pressure treatment of $\mathrm{C}_{70}$. J. Phys. Chem. B 104, 4101-4110.

Leger, A. \& d'Hendecourt, L. (1985). Are polycyclic aromatic hydrocarbons the carriers of the diffuse interstellar bands in the visible? Astron. Astrophys. 146, 81-85.

Le Page, V., Snow, T.P. \& Bierbaum, V.M. (2001). Hydrogenation and Charge States of PAHS in Diffuse Clouds. I. Development of a Model. Astrophys. J. Suppl. 132(2), 233-251.

Malloci, G., Mulas, G. \& Joblin, C. (2004). Electronic absorption spectra of PAHs up to vacuum UV: towards a detailed model of interstellar PAH photophysics. Astron. Astrophys. 426, 105-117.

Malloci, G., Mulas, G., Cecchi-Pestellini, C. \& Joblin, C. (2008) Dehydrogenated polycyclic aromatic hydrocarbons and UV bump. Astron. Astrophys. 489, 1183-1187.

Mattioda, A.L., Bauschlicher, C.W. Jr., Bregman, J.D., Hudgins, D.M., Allamandola, L.J. \& Ricca, A. (2014). Infrared vibrational and electronic transitions in the dibenzopolyacene family. Spectrochim. Acta A: Mol. Biomol. Spectrosc. 130, 639-652.

Miles, A.J., Hoffmann, S.V., Tao, Y., Janes, R.W. \& Wallace, B.A. (2007). Synchrotron radiation circular dichroism (SRCD) spectroscopy: new beamlines and new applications in biology. Spectroscopy 21, 245-255.

Miles, A.J., Janes, R.W., Brown, A., Clarke, D.T., Sutherland, J.C., Tao, Y., Wallace, B.A. \& Hoffmann, S.V. (2008). Light flux density threshold at which protein denaturation is induced by synchrotron radiation circular dichroism beamlines. J. Synchrotron Radiat. 15, 420-244.

Montillaud, J., Joblin, C. \& Toublanc, D. (2013). Evolution of polycyclic aromatic hydrocarbons in photodissociation regions Hydrogenation and charge states. Astron. Astrophys. 552, A15.

Pascoli, G. \& Polleux, A. (2000). Condensation and growth of hydrogenated carbon clusters in carbon-rich stars. Astron. Astrophys. 359, 799.

Pullman, A. \& Pullman, B. (1955). Electronic structure and carcinogenic activity of aromatic molecules: new developments. Adv. Cancer Res. 3 , 117-169.

Rabbow, E., Rettberg, P., Barczyk, S., Bohmeier, M., Parpart, A., Panitz, C., Horneck, G., Burfeindt, J., Molter, F., Jaramillo, E. et al. (2014). The astrobiological mission EXPOSE-R on board of the International Space Station. Int. J. Astrobiol., this issue.

Ruiterkamp, R., Cox, N.L.J., Spaans, M., Kaper, L., Foing, B. H., Salama, F. \& Ehrenfreund, P. (2005). PAH charge state distribution and DIB carriers: Implications from the line of sight toward HD 147889. Astron. Astrophys.432, 515-529.

Salama, F. (2008). PAHs in astronomy. A review. In Organic Matter in Space Proceedings, ed. Kwok, S. \& Sandford, S., IAU Symposium 251, pp. 357-365.

Salama, F., Bakes, E.L.O., Allamandola, L.J. \& Tielens, A.G.G.M. (1996). Assessment of the polycyclic aromatic hydrocarbon-diffuse interstellar band proposal. Astrophys. J. 458, 621-636.

Sandford, S.A., Bajt, S., Clemett, S.J., Cody, G.D., Cooper, G., Degregorio, B.T., De Vera, V., Dworkin, J.P., Elsila, J.E., Flynn, G.J. et al. (2010). Assessment and control of organic and other contaminants associated with the Stardust sample return from comet 81P/Wild 2. Meteoritics $\mathbf{4 5}$, 406-433.

Schettino, V., Pagliai, M. \& Cardini, G. (2002). the infrared and raman spectra of fullerene $\mathrm{C}_{70}$. DFT calculations and correlation with $\mathrm{C}_{60}$. J. Phys. Chem. A 106, 1815-1823.

Sellgren, K., Werner, M., Ingalls, J., Smith, J.D.T., Carleton, T.M. \& Joblin, C. (2010). $\mathrm{C}_{60}$ in reflection nebulae. Astrophys. J. Lett. 722, L54-L57.

Sephton, M.A., Phillinger, C.T. \& Gilmour, I. (1998). 813 C of free and macromolecular aromatic structures in the murchison meteorite. Geochim. Cosmochim. Acta 62, 1821-1828.

Sonnentrucker, P., Cami, J., Ehrenfreund, P. \& Foing, B.H. (1997). The diffuse interstellar bands at 5797, 6379 and 6613 Angstroms. Ionization properties of the carriers. Astron. Astrophys. 327, 1215-1221.

Tielens, A.G.G.M. (2008). Interstellar polycyclic aromatic hydrocarbon molecules. Anпu. Rev. Astron. Astrophys. 46, 289-337.

Vuong, M.H. \& Foing, B.H. (2000). Dehydrogenation of polycyclic aromatic hydrocarbons in the diffuse interstellar medium. Astron. Astrophys. 363, L5-L8. 